\title{
Peptic ulcer surgery: selection for operation by 'earning'
}

\author{
W. P. SMALL, E. L. CAY, P. DUGARD, W. SIRCUS, C. W. A. FALCONER, \\ A. N. SMITH, J. P. A. MCMANUS, AND SIR JOHN BRUCE \\ From the Gastro-Intestinal Unit at Western General Hospital, Edinburgh, M.R.C. Unit for \\ Research into the Epidemiology of Nervous and Mental Diseases, Edinburgh, and the Department \\ of Statistics, University of Edinburgh
}

SUMmARY Two groups of patients with chronic peptic ulcer were studied to determine the influence of duration of symptoms and age at operation on the result of surgical treatment.

Independent physical and psychiatric assessments were made.

Statistical analysis of the findings indicates that selection for operation by 'earning' is unreliable in that it fails to identify that group of patients liable to do badly. In its place, a combined physical and psychiatric preoperative assessment of the peptic ulcer patient is recommended.

It has long been believed that the best results of surgely for peptic ulcer are found in those patients who have suffered the effects of ulcer over a considerable period of years. The term 'earning' operation for peptic ulcer, attributed to Gordon-Taylor (Edwards, 1961), describes the practical application of this belief to selection for surgery.

Although most operations for ulcer may be followed by side effects such as dumping and postprandial discomfort, relatively few patients return with complaints. They tolerate these sequelae, dismissing them, so it is implied, as a minor price to pay for relief from ulcer pain (Illingworth, 1953). Thus it is argued that the patient with a short history of minor symptoms is unlikely to accept the after effects of operation and may well magnify them to the extent of becoming a 'gastric cripple'. It could be in the best interests of such a patient, therefore, to delay operation until it is certain that the ulcer symptoms have left an indelible imprint on his mind.

These ideas relating length and severity of ulcer history to the result of operation have been embellished over the years. Many surgeons who support Gordon-Taylor's dictum believe that 'earning' is a means of detecting the psychiatrically ill patient. In the view of such surgeons these patients are intolerant of modest ulcer symptoms, seek early operation and do badly. Thus Visick (1948) came to refuse gastrectomy to patients with psychiatric disorder, stating that 'operation in patients with a pronounced neurotic overlay left too large a legacy of failure'. Capper (1952) equated disorder of the psyche with the age of the patient and warned that 'intense obsessional young men will need carefu' consideration'.

But can these widely adopted views be accepted without question? Do the results of surgery for peptic ulcer depend on the age of the patient, the duration of symptoms, or their severity? Is operation to be avoided in psychoneurotic patients? Do such patients seek operation earlier in the history of the disease or at a younger age than their more stable counterparts?

We sought to answer these points by a review of our experience in the Gastro-Intestinal Unit.

Two separate groups of patients were studied.

$$
\text { FIRST STUDY (GROUP A) }
$$

One hundred and forty-seven patients drawn from the Gastric Follow-up Clinic were interviewed and re-assessed. All had been treated for proven duodenal ulcer by a variety of operations (Table I) and none less than five years before review (Table II).

On average, these patients had an ulcer history of 12 years before operation, with a range of seven months to more than 25 years. The youngest was under 20 years, the oldest over 70 years of age at the time of operation.

At follow up, most patients made the familiar statement that they "should have had the operation years ago', but only 20 had had surgery deliberately postponed. Forty-nine had suffered delay in coming to operation for a variety of reasons (Table III). 
TABLE I

OPERATIONS USED IN TREATMENT OF DUODENAL ULCER IN GROUP A

Operation No. of Patients

Polya gastrectomy

Billroth I gastrectomy

Gastroenterostomy

Truncal vagotomy

Truncal vagotomy + Polya gastrectomy

Truncal vagotomy + gastroenterostomy

Selective vagotomy + gastroenterostomy

Truncal vagotomy + pyloroplasty

Selective vagotomy + pyloroplasty

Closure of perforation

Total in group

119

1

3

1

7

7

6

$\mathbf{1}$

147

TABLE II

DURATION OF FOLLOW-UP IN GROUP A

Years of Age

No. of Patients

0- 4

5. 9

$10-14$

15-19

20-24

$25 \&$ over

0
82
20
44
1
0

TABLE III

REASONS FOR DELAY IN OPERATION IN GROUP A

Reason for Delay

No. of Patients

Referral refused by family doctor

Operation refused by hospital

Failure of diagnosis

Operation never suggested

Total

9

11

20

29

69

The result of operation was expressed as good, moderate, or bad according to the criteria of Visick as modified by Pulvertaft in 1952 (Table IV).

No attempt was made to determine the psychiatric status of patients in this surgical group, either preoperatively or when seen for review.

\section{RESULTS OF FIRST STUDY}

Relation of duration of symptoms and age of the patient to outcome One hundred and fourteen patients $(77.5 \%)$ were judged to have a good post- operative result (Visick grade 1 or 2). When the length of preoperative symptoms was related to the outcome of operation, it was found that the proportion of good results in each duration group did not differ more than would be expected by chance (Figure 1 and Table Va). Similarly, the age at opera-

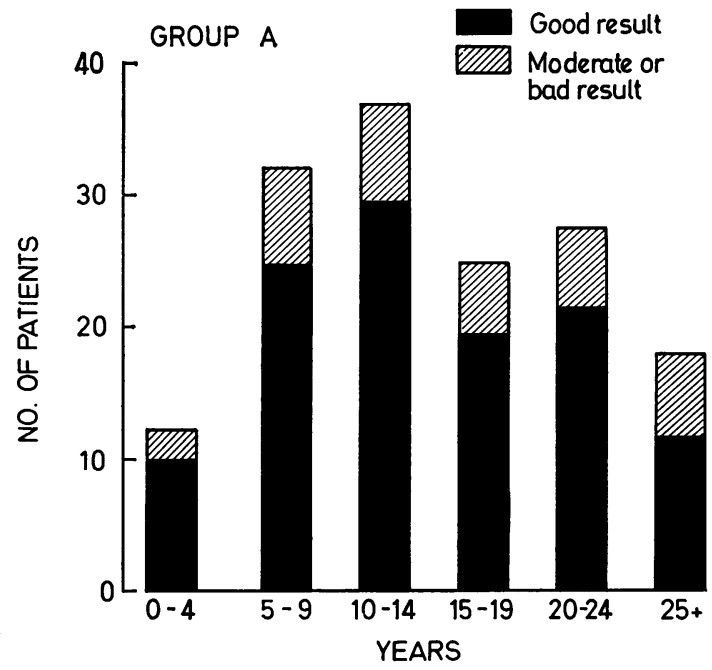

FIG. 1. Duration of symptoms and age of patient related to outcome.

tion did not influence the outcome, the proportion of good results being similar in all age groups (Figure 2 and Table $\mathrm{Vb}$ ).

But ail duodenal ulcers may not have the same aetiology and natural history. A man of, say, 40 with a 20-year history may have a different type of ulcer from a man of $\mathbf{4 0}$ with a five-year history. Likewise, a 20-year history of ulcer starting in childhood might have a different significance from a 20-year history starting in middle age. Age and duration were therefore considered together in relation to the outcome of operation (Table Vc). The proportion of good results was similar for all age-duration groups.

\section{TABLE IV}

RATING OF PHYSICAL OUTCOME (VISICK, 1948, AND PULVERTAFT, 1952)

1 No symptoms

2 Mild symptoms easily controlled, eg, mild dumping which was suppressed by patient's adjusting his eating habits slightly

3s Mild symptoms not controlled (satisfactory), eg, episodes of bilious vomiting at regular intervals, but the patient denied any real disability from this

3u Mild symptoms not controlled (unsatisfactory), eg, the patient suffered from residual symptoms severe enough to restrict his life, and in some instances suggested that he had been better off with his ulcer

4 Not improved, eg, recurrence of ulcer after surgery, readmission to hospital on account of residual symptoms, or a second definitive operation was necessary 
TABLE Va

RESULT RELATED TO DURATION OF SYMPTOMS IN GROUP $A^{1}$

Result

Duration of Symptoms in Years

\begin{tabular}{|c|c|c|c|c|c|c|c|}
\hline & & \multirow[b]{2}{*}{$20-24$} & \multirow[b]{2}{*}{$25 \div-$} & \\
\hline & $0-4$ & $5-9$ & $10-14$ & $15-19$ & & & \\
\hline Good & $\begin{array}{l}10 \\
(83 \%)\end{array}$ & $\begin{array}{l}25 \\
(78 \%)\end{array}$ & $\begin{array}{l}30 \\
(81 \%)\end{array}$ & $\begin{array}{l}18 \\
(78 \%)\end{array}$ & $\begin{array}{l}20 \\
(77 \%)\end{array}$ & $\begin{array}{l}11 \\
(65 \%)\end{array}$ & 114 \\
\hline Moderate or bad & 2 & 7 & 7 & 5 & 6 & 6 & 33 \\
\hline Total & 12 & 32 & 37 & 23 & 26 & 17 & 147 \\
\hline
\end{tabular}

${ }^{1}$ There is no increase in the proportion of good results with increasing duration of symptoms.

TABLE Vb

RESULT RELATED TO AGE OF PATIENT IN GROUP $A^{1}$

Result

Age in Years

\begin{tabular}{lllllllll} 
& \multicolumn{1}{c}{$10-19$} & $20-29$ & $30-39$ & $40-49$ & $50-59$ & $60-69$ & $70 \div-$ \\
\hline Good & 1 & 12 & 25 & 33 & 38 & 4 & 1 \\
Moderate or bad & $(100 \%)$ & $(92 \%)$ & $(69 \%)$ & $(75 \%)$ & $(86 \%)$ & $(57 \%)$ & $(100 \%)$ & 114 \\
Total & 0 & 1 & 11 & 12 & 6 & 3 & 0 & 33 \\
& 1 & 13 & 36 & 45 & 44 & 7 & 1 & 147
\end{tabular}

'There is no increase in the proportion of good results with increasing age.

TABLE Vc

(jOOD RESULTS RELATED TO DURATION OF SYMPTOMS AND AGE OF PATIENT IN GROUP $A^{1}$

Age Group

Duration of Symptoms in Years

Total

$0-4 \quad 5-14 \quad 15$

\begin{tabular}{lcccc}
\hline $10-29$ & 2 & 10 & 1 & 13 \\
$30-49$ & $(100 \%)$ & $(91 \%)$ & $(100 \%)$ & \\
& 3 & 28 & $27 \%$ & 58 \\
50 & $(75 \%)$ & $(74 \%)$ & $(69 \%)$ & 43 \\
& $(83 \%)$ & $(85 \%)$ & $(81 \%)$ & \\
Total & 10 & 55 & 49 & 114
\end{tabular}

'The proportions of good results in the nine age-duration cells do not differ significantly $\left(x^{2} \cdots 1 \cdot 08\right)$.

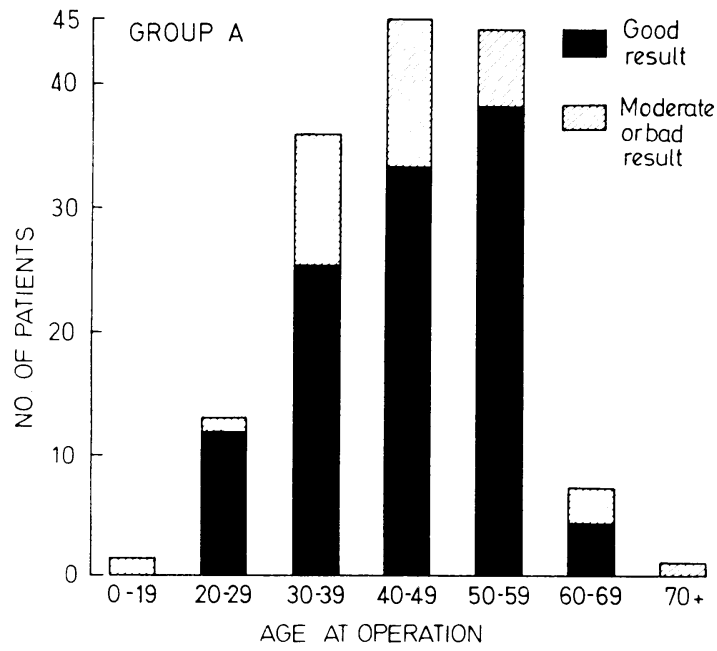

FIG. 2. Histogram illustrating that age at operation did not influence the outcome.
Relation of delay in operation to outcome The data suggest that 'earning' is not related to the outcome of operation. But it could be said that of the whole group only 69 patients had suffered delay (Table III) and had truly 'earned' their operation.

When the result of operation in these 69 is compared with that of the remainder, it is seen that the proportion of patients with a good result is the same whether or not delay had occurred (Table VI).

\section{TABLE VI}

RESULT IN PATIENTS SUFFERING DELAY COMPARED WITH THE REST IN GROUP A

\begin{tabular}{lllr} 
Assessment & $\begin{array}{l}\text { Operation } \\
\text { Delayed }\end{array}$ & $\begin{array}{l}\text { Operation } \\
\text { Not Delayed }\end{array}$ & Total \\
\hline Good result & 51 & 63 & 114 \\
Moderate or bad result & 18 & 15 & 33 \\
Total & 69 & 78 & 147
\end{tabular}

$\left[x_{1}{ }^{2}:=0.99(P>0.1)\right]$

Outcome of operation in patients with a short history Conversely, patients with a short history could be said to be 'non-earners'. Occasionally a patient comes to operation almost immediately. If perforation or haemorrhage is the presenting sign of the ulcer, there may be little or no antecedent dyspepsia. Such patients, if the idea of 'earning' be correct, should complain of the sequelae of operation. No patient in our series presented without some premonitory history. The shortest history was seven months. There were 12 patients who had had symptoms for less than five years. In these, the result of operation five or more years later was good 
in 10-an outcome comparable with that in those patients who had suffered for a considerable length of time before operation.

\section{SECOND STUDY (GROUP B)}

There were 178 patients in this group. They differed from group $\mathbf{A}$ in three important respects. First, they had been referred to the Unit for treatment of ulcer symptoms at least 10 years after group A. Secondly, each patient, in addition to being examined clinically by the physicians and surgeons, was psychiatrically assessed before conventional treatment of the ulcer. Thirdly, the group included 28 cases of primary gastric ulcer. The diagnoses of the group are shown for both sexes in Table VII. The distributions of age, sex, length of history, and type of ulcer in these patients are typical of hospital peptic ulcer populations in Great Britain and the USA (Jones, 1956; Susser, 1967; Johnson, 1962; Gainsborough and Slater, 1946).

One hundred and twenty-two $(68.5 \%)$ were judged to have clear evidence of some psychiatric disorder (Table VIII). All patients in the group were kept under observation for 30 months without being given specific psychiatric treatment. During this period, 98 of the 178 patients came to surgery

\section{TABLE VII}

SEX DISTRIBUTION AND DIAGNOSIS IN GROUP B

\begin{tabular}{|c|c|c|c|}
\hline Diagnosis & Male & Female & Total \\
\hline Duodenal ulcer & $\begin{array}{l}106 \\
(77 \cdot 4 \%)\end{array}$ & $\begin{array}{l}31 \\
(22.6 \%)\end{array}$ & $\begin{array}{l}137 \\
(100 \%)\end{array}$ \\
\hline Gastric ulcer & $\begin{array}{l}16 \\
(57 \cdot 1 \%)\end{array}$ & $(42.9 \%)$ & $\begin{array}{c}28 \\
(100 \%)\end{array}$ \\
\hline Duodenal and gastric ulcer & $\begin{array}{c}11 \\
(84 \cdot 6 \%)\end{array}$ & $\stackrel{2}{(15.4 \%)}$ & $\begin{array}{l}13 \\
(100 \%)\end{array}$ \\
\hline
\end{tabular}

TABLE VIII

PSYCHIATRIC DIAGNOSIS AT INITIAL INTERVIEW IN GROUP B

Diagnosis

\section{Depression}

Anxiety

Character disorder only

Organic psychosis

Other psychoses

Without psychiatric symptoms

Total

No. of Patients

48
41
30
1
2
56
178

(Table IX). Of the 98, $64(65 \%)$ had been diagnosed at their initial assessment as being psychiatrically ill. But neither pre- nor postoperatively were the physicians or surgeons of the Unit informed of the results of these psychiatric studies so that their choice of treatment, whether medical or surgical, and their opinion of its results could remain unbiased.

After operation the results, both physical and psychiatric, were assessed and recorded independently at six-monthly intervals over the duration of follow up. The physical outcome was assessed as in group A according to Visick's criteria (Table IV). The psychiatric outcome was judged to be good, unchanged, or bad as compared with the preoperative assessment (Table X). At the 30-month follow up, 10 of the 98 surgical patients were not seen (nine of the 64 with psychiatric symptoms and one of the 34 without).

\section{TABLE $X$}

RATING OF PSYCHIATRIC OUTCOME IN GROUP B

1 Symptoms gone
2 Symptoms better
3 No change in sympt
4 Symptoms worse
5 New symptoms, ie,
course of follow up in
at initial interview.
Good $=1+2$
Unchanged $=3$
Bad $=4+5$

GENERAL CHARACTERISTICS OF GROUP B PATIENTS TREATED SURGICALLY The 98 patients in group B who were treated surgically for ulcer showed the same general characteristics in respect of duration of symptoms and age at operation as group $A$ (Tables XI and XII). The youngest was under 20 years of age and the oldest over 70 years at the time of operation, and the length of ulcer symptoms ranged from 1.5 years to 50 years.

\section{RESULTS OF SECOND STUDY}

Toleration of ulcer symptoms If the psychiatric patient is intolerant of his symptoms, then he will present for operation at a young age or with a short length of history. The patients with psychiatric symptoms were slightly younger (mean 41.8 years) than those without psychiatric symptoms (mean

TABLE IX

PSYCHIATRIC DIAGNOSIS AT INITIAL INTERVIEW RELATED TO SUBSEQUENT PHYSICAL TREATMENT IN GROUP B

Subsequent Treatment

\begin{tabular}{lrll} 
Assessment & Total Group & Surgical & Medical \\
\cline { 3 - 4 } With psychiatric symptoms & $122(69 \%)$ & $64(65 \%)$ & $34(35 \%)$ \\
Without psychiatric symptoms & $56(31 \%)$ & $98(100 \%)$ & $(72 \%)$ \\
Total & $178(100 \%)$ & &
\end{tabular}


TABLE XI

DURATION OF SYMPTOMS BEFORE OPERATION IN PATIENTS WITH AND WITHOUT PSYCHIATRIC SYMPTOMS IN GROUP B

\begin{tabular}{llll} 
Duration $(y r)$ & \multicolumn{2}{c}{ Psychiatric Symptoms } & Total \\
\cline { 2 - 3 } & No. with & No. without & \\
\hline $0-4$ & 6 & 5 & 11 \\
$5-9$ & 12 & 7 & 19 \\
$10-14$ & 22 & 6 & 28 \\
$15-19$ & 8 & 6 & 14 \\
$20-24$ & 8 & 5 & 13 \\
$25+$ & 8 & 5 & 13 \\
Total & 64 & 34 & 98
\end{tabular}

TABLE XII

AGE AT OPERATION IN PATIENTS WITH AND WITHOUT PSYCHIATRIC SYMPTOMS IN GROUP B

\begin{tabular}{lllr}
\multirow{2}{*}{ Age $(y r)$} & \multicolumn{2}{c}{ Psychiatric Symptoms } & Total \\
\cline { 2 - 4 } & No. with & No. without & \\
\hline $0-9$ & - & - & - \\
$10-19$ & - & 1 & 1 \\
$20-29$ & 8 & 4 & 28 \\
$30-39$ & 24 & 4 & 20 \\
$40-49$ & 13 & 7 & 26 \\
$50-59$ & 15 & 11 & 10 \\
$60-69$ & 4 & 6 & 1 \\
$70+$ & - & 1 & 98 \\
Total & 64 & 34 &
\end{tabular}

47.6 years) but the average ages fell within the same decade (Table XII). There was, however, no significant difference in the length of history before operation (Table XI). (Psychoneurotic patients had a mean history of 14.2 years, compared with a mean history of $16 \cdot 1$ years for the remainder of the group.) Thus in our series, there is no evidence that the psychiatric patient comes to surgery at an earlier stage in his ulcer history than does the normal patient.

Duration of symptoms and age of patient related to physical result In exactly the same way as in group A the outcome of operation was examined in relation to the length of history and the age of the patient (Tables XIII and XIV). These short-term results of surgery were uninfluenced by the duration of the patient's symptoms or his age. Six of the 64 psychoneurotic patients and five of the 34 normal patients had a history of less than five years. The proportions of patients with minimal symptoms in these two subgroups did not differ significantly. Ten of the 11 patients had a good result (five psychiatric and five non-psychiatric) an outcome at least as good as in the remainder of the patients who had suffered from ulcer dyspepsia over a longer period of time.

Thus, neither in the short nor in the long term

TABLE XIII

DURATION OF SYMPTOMS RELATED TO PHYSICAL RESULT AT 30 MONTHS IN GROUP B $^{1}$

\begin{tabular}{|c|c|c|c|c|c|}
\hline \multirow{2}{*}{ Duration of Symptoms (yr) } & \multicolumn{2}{|c|}{ Patients with Psychiatric Symptoms } & \multicolumn{2}{|c|}{ Patients without Psychiatric Symptoms } & \multirow[t]{2}{*}{ Total } \\
\hline & No. of Patients Seen & Good Result & No. of Patients Seen & Good Result & \\
\hline $0-4$ & 6 & 5 & 5 & 5 & 11 \\
\hline 5- 9 & 9 & 7 & 7 & 5 & 16 \\
\hline $10-14$ & 20 & 13 & 6 & 5 & 26 \\
\hline $15-19$ & 7 & 4 & 5 & 5 & 12 \\
\hline $20-24$ & 8 & 5 & 5 & 4 & 13 \\
\hline $25+$ & 5 & 4 & 5 & 5 & 10 \\
\hline Total & 55 & 38 & 33 & 29 & 88 \\
\hline
\end{tabular}

${ }^{1}$ Nine patients without and one patient with psychiatric symptoms were not seen at 30 -month follow up

TABLE XIV

AGE AT OPERATION RELATED TO PHYSICAL RESULT AT 30 MONTHS IN GROUP $\mathbf{B}^{1}$

\begin{tabular}{|c|c|c|c|c|c|}
\hline \multirow[t]{2}{*}{ Age of Patient (yr) } & \multicolumn{2}{|c|}{ Patients with Psychiatric Symptoms } & \multicolumn{2}{|c|}{ Patients without Psychiatric Symptoms } & \multirow[t]{2}{*}{ Total } \\
\hline & No. of Patients Seen & Good Result & No. of Patients Seen & Good Result & \\
\hline 0- 9 & - & - & - & - & - \\
\hline $10-19$ & - & - & 1 & 1 & 1 \\
\hline $20-29$ & 7 & 6 & 4 & 3 & 11 \\
\hline $30-39$ & 22 & 16 & 4 & 4 & 26 \\
\hline $40-49$ & 9 & 7 & 6 & 5 & 15 \\
\hline $50-59$ & 13 & 8 & 11 & 9 & 24 \\
\hline $60-69$ & 4 & 1 & 6 & 6 & 10 \\
\hline $70+$ & - & - & 1 & 1 & 1 \\
\hline Total & 55 & 38 & 33 & 29 & 88 \\
\hline
\end{tabular}

Nine patients without and one patient with psychiatric symptoms were not seen at 30-month follow up 

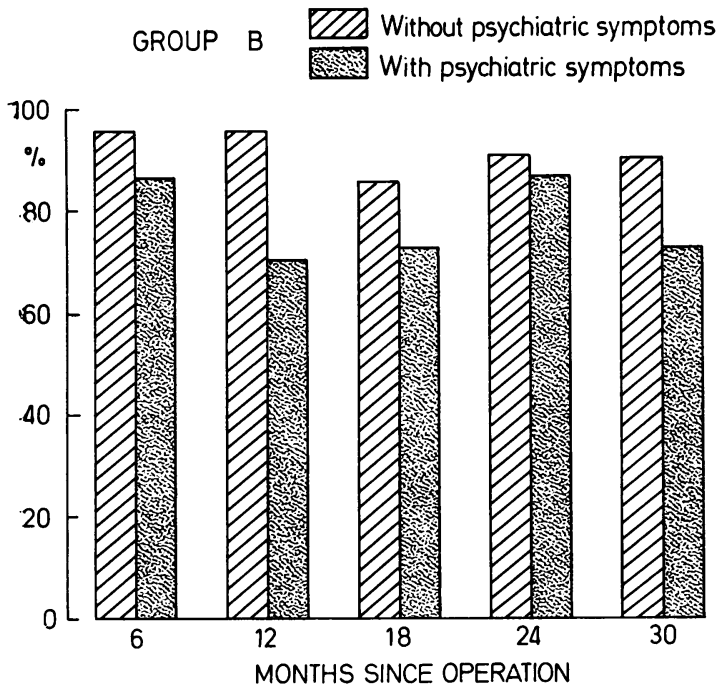

FIG. 3. Histogram relating the physical results of surgery to the stability or otherwise of the patient.

results of surgery for chronic peptic ulcer is there support for the concept of 'earning'. Better results are not achieved in patients who have suffered from ulcer dyspepsia for a considerable time, nor is the outcome bettered by delay in operation. We now consider the results of surgery in patients with psychoneurotic symptoms.

Effect of operation on the psychiatrically ill patient (1) Is the physical result disappointing in that psychiatrically ill patients are prone to develop dumping, bile vomiting, and other postoperative upsets?

The good physical results of surgery in the 64 patients of group B labelled as having psychiatric symptoms are compared with those in the 34 stable patients in Figure 3. The results 30 months after operation provide justification for the claim that the psychoneurotic patient does less well than the stable patient (Table XV). But good physical results were obtained in at least seven out of every 10 psychiatric patients, a picture which is not nearly so pessimistic as has been suggested by others. Even without the benefit of formal psychiatric therapy, these neurotic patients profit from surgery.

(2) Does the patient deteriorate psychiatrically after operation? Another argument against operation in the psychiatrically ill patient admits the possibility of a good physical result while claiming that in psychological terms removal of ulcer symptoms deprives these patients of a means of escape (Browning and Houseworth, 1953). They then no longer have the excuse of their dyspepsia to shield them from upsetting situations and therefore they deterior-
TABLE XV

PHYSICAL RESULTS AT 30 MONTHS IN PATIENTS WITH AND WITHOUT PSYCHIATRIC SYMPTOMS IN GROUP $\mathbf{B}^{1}$ Assessment

\begin{tabular}{llll} 
& \multicolumn{2}{l}{ Psschiatric Symptoms } & \\
\cline { 2 - 3 } & No. with & No. without & \\
\hline Good physical result & 38 & 29 & 67 \\
Moderate or bad physical result & 17 & 4 & 21 \\
Total & 55 & 33 & 88
\end{tabular}

${ }^{1}$ Nine patients without and one patient with psychiatric symptoms were not seen at 30-month follow up.

$\left[x_{1}{ }^{2}=4.01 \quad(P<0.05)\right]$

ate psychiatrically. Ely and Johnson (1966) state that 'it appears that gastrectomy with its relief of ulcer symptoms was instrumental in pushing these new (psychiatric) symptoms into significance'.

Our results do not support this claim, for we find that among the 55 psychiatrically ill patients seen at the 30-month follow up, good physical and good psychiatric results are associated (Table XVI).

\section{TABLE XVI}

ASSOCIATION OF PSYCHIATRIC AND PHYSICAL RESULTS IN GROUP $\mathbf{B}^{\mathbf{1}}$

\begin{tabular}{lll} 
Assessment & $\begin{array}{l}\text { Good } \\
\text { Psychiatric Result }\end{array}$ & $\begin{array}{l}\text { Unchanged or Bad Total } \\
\text { Psychiatric Result }\end{array}$ \\
\hline
\end{tabular}

Good physical

result

physical result

$\begin{array}{rll}22 & 16 & 38 \\ 2 & 15 & 17 \\ 24 & 31 & 55\end{array}$

$\begin{array}{lcc}\text { Total } & 24 & 31 \\ & & \end{array}$

$\left[x_{1}{ }^{2}=10.16(\mathrm{P}<0.01)\right]$

THE SEVERITY OF THE ULCER RELATED TO THE OUTCOME OF OPERATION

Duration may not be indicative of severity. A severe ulcer could be defined as one responsible for the complications of haemorrhage, stenosis, or previous perforation. According to these criteria, $48(32.6 \%)$ of the 147 patients in group $A$ had a severe ulcer. Forty of the 48 had a good result of operation. Ninety-nine patients did not have a severe ulcer, of whom 74 had a good result. There is no significant difference between these groups $\left(\chi_{1}{ }^{2}=1 \cdot 37\right)$.

In group B, $42(42 \cdot 8 \%)$ of the 98 patients coming to surgery had a severe ulcer: 23 of the 64 patients with psychiatric symptoms and 19 of the 34 without psychiatric symptoms (Table XVII). In patients without psychiatric symptoms the good results of surgery do not depend on the severity of the ulcer (Table XVIII). The bad results of surgery are concentrated in that group of patients with psychiatric symptoms but without severe ulcer. 
TABLE XVII

SEVERITY OF ULCER IN PATIENTS WITH AND WITHOUT PSYCHIATRIC SYMPTOMS IN GROUP B

\begin{tabular}{llll} 
Type of Ulcer & \multicolumn{2}{c}{ Psychiatric Symptoms } & Total \\
\cline { 2 - 4 } & No. with Symptoms & No. without Symptoms \\
\hline Severe & 23 & 19 & 42 \\
Not severe & 41 & 15 & 56 \\
Total & 64 & 34 & 98
\end{tabular}

less severe ulcer disease. In our series, operation is successful in less than $60 \%$ of patients with this combination. This is the subgroup that it is important to identify. 'Earning' is an unreliable guide to its recognition because severity of ulceration cannot be equated with the duration of a patient's symptoms or his age. Furthermore, compared with his stable counterpart, the psychiatrically ill patient

$\left[x_{1}{ }^{2}=3.61(P>0.05)\right]$

TABLE XVIII

SEVERITY OF ULCER AND PHYSICAL OUTCOME OF OPERATION AT 30 MONTHS IN GROUP B

\begin{tabular}{|c|c|c|c|c|}
\hline \multirow[t]{2}{*}{ Type of Ulcer } & \multicolumn{2}{|c|}{$\begin{array}{l}\text { Patients with Psychiatric Symptoms } \\
\text { (Nine Missing at } 30 \text { Months) }\end{array}$} & \multicolumn{2}{|c|}{$\begin{array}{l}\text { Patients without Psychiatric Symptoms } \\
\text { (One Missing at } 30 \text { Months) }\end{array}$} \\
\hline & Good Physical Result & Moderate or Bad Physical Result & Good Physical Result & Moderate or Bad Physical Result \\
\hline $\begin{array}{l}\text { Severe } \\
\text { Not severe }\end{array}$ & $\begin{array}{l}18 \\
20\end{array}$ & $\begin{array}{l}2 \\
15\end{array}$ & $\begin{array}{l}18 \\
11\end{array}$ & $\begin{array}{l}1 \\
3\end{array}$ \\
\hline Total & 38 & ${ }^{17}\left[x_{1}^{2}=6.43(P<0.05)\right]$ & $\begin{array}{l}29 \\
=1.98(P>0.05)]\end{array}$ & 4 \\
\hline
\end{tabular}

\section{DISCUSSION}

It would appear from this study that the chance of a good result of surgery is not greater in the patient who might be considered to have 'earned' his operation. The proportion of good results is very similar whatever the duration of symptoms or the age of the patient. This is true for both series of patients considered here. The concept of 'earning' appears to be an unreliable guide to the surgeon faced with the need to decide whether or not a patient with chronic peptic ulcer merits surgical treatment.

Among the group B patients there is some support for the view that a good result of surgery is less likely if the patient is found to have a coexisting psychiatric disability. The difference between the proportions of good results among the patients with and without psychiatric symptoms is just statistically significant. Even so, $\mathbf{3 0}$ months after operation almost $70 \%$ of patients with psychiatric symptoms have a good physical result. We found no evidence to support the view that successful surgery will exacerbate psychiatric symptoms. On the contrary, the better the physical result of surgery the better is the chance of psychiatric improvement.

The findings with regard to the severity of the ulcer are contradictory. In group A, the proportions of good results are the same whether or not the patient was classed as having severe ulcer disease. In group B, this statement is true for the patient without psychiatric symptoms, but in those with psychiatric symptoms the outcome of surgery is influenced by the severity of the ulceration. The poor results in group B are concentrated in those patients shown to have psychiatric symptoms coupled with comes to hospital no earlier in the course of his ulcer disease.

Our study leads us to recommend the adoption of a combined physical and psychiatric assessment.

First, it is necessary to confirm that the patient has an ulcer and that the ulcer merits surgical treatment. As a rough guide to the severity of the ulcer, we have used the presence of stenosis, or a history of previous perforation or bleeding. Such reservations might seem elementary, yet from the literature it is obvious that gastric surgery is at times employed in the absence of proper indications and in the forlorn hope of it doing good (Johnstone, Holbitsky, and Debas, 1967). Secondly, the patient's psychiatric status must be assessed. We have used simple and conventional proformata. These, we believe, could be completed by the clinician and the correct conclusions drawn without recourse to specialized psychiatric help. At the present moment, it would seem to us that one should be cautious in offering surgery to the psychiatrically abnormal patient who does not have a severe ulcer.

We have concerned ourselves with the results of surgery in the absence of psychiatric treatment and this conclusion disregards the possible contribution that such treatment might make to the outcome. For the future, a higher proportion of good results might be obtainable in these bad-risk patients because we have evidence from other studies to suggest that, in duodenal ulcer at least, pre- and postoperative psychiatric treatment of the psychiatrically ill patient will improve the chances of a good physical and psychiatric outcome. Such a policy implies cooperation between clinician and psychiatrist from the outset in those patients with 
psychiatric symptoms and is contrary to the common practice whereby only when failure is obvious postoperatively is the patient referred to the psychiatrist. By then it may be too late. Psychiatric deterioration has been added to physical failurean outcome which we believe is avoidable.

Our thanks are due to Professor W. I. Card, whose interest in the selection of the patient for operation stimulated us to embark on this study.

We are grateful to Professor G. M. Carstairs and Professor D. J. Finney for much helpful advice and criticism.

The Gastric Follow-up Clinic in which the results of surgery were assessed is supported by the South-Eastern Regional Hospital Board (Scotland).

\section{REFERENCES}

Browning, J. S., and Houseworth, J. H. (1953). Development of new symptoms following medical and surgical treatment for duodenal ulcer. Psychosom. Medicine, 15, 328-336.

Capper, W. M. (1952). After gastrectomy. In Modern Trends in Gastro-enterology, p. 463 . Edited by F. Avery Jones. Butterworth, London.

Edwards, H. C. (1961). The surgical treatment of chronic peptic ulceration. Practitioner, 186, 328-334.

Ely, N. E., and Johnson, M. H. (1966). Emotional responses to peptic ulcer management. Amer. J. Psychiat., 122, 1362-1371.

Gainsborough, H., and Slater, E. (1946). Study of peptic ulcer. Brit. med. J., 2, 253-258.

Illingworth, C. F. W. (1953). Peptic Ulcer, p. 165. Livingstone Edinburgh.

Johnson, H. D. (1962). Peptic ulcer in hospital: an analysis of a $10 \%$ in-patient enquiry throughout England and Wales. Gut, 3, 106-117.

Johnstone, F. R. C., Holbitsky, I. B., and Debas, H. T. (1967). Post-gastrectomy problems in patients with personality defects: the 'albatross' syndrome. Canad. med. Ass. J., 96, 1559-1564.

Jones, F. A. (1956). Problem of peptic ulcer. Ann. intern. Med., 44, 63-77.

Pulvertaft, C. M. (1952). The results of partial gastrectomy for peptic ulcer. Lancet, 1, 225-231.

Susser, M. (1967). Causes of peptic ulcer: a selected epidemiological review. J. chron. Dis., 20, 435-456.

Visick, A. H. (1948). Measured radical gastrectomy. Lancet, 1, 505$510,551-555$. 